\title{
ANÁLISE DO CUSTO DE EDIFICAÇÕES DEVIDO A UTILIZAÇÃO DE BLOCOS CERÂMICOS NÃO NORMATIZADOS*
}

\author{
Noan Tonini Simonassi ${ }^{1}$ \\ Sergio Neves Monteiro ${ }^{2}$ \\ Afonso Rangel Garcez de Azevedo ${ }^{3}$ \\ Jonas Alexandre ${ }^{4}$ \\ Gustavo de Castro Xavier ${ }^{5}$ \\ Rodolfo Cretton Souza ${ }^{6}$ \\ Euzébio Barnabé Zanelato ${ }^{7}$
} Resumo

A indústria da construção civil e a que mais absorve mão-de-obra no Brasil, com uma significativa participação no PIB, da ordem de $15 \%$. Em contrapartida e ainda apontada como uma grande geradora de resíduos, que variam em função da matéria-prima utilizada e também da mão-de-obra desqualificada. Dentro desta faixa de mercado, o número de edificações que empregam blocos cerâmicos como elementos de vedação ou estruturais, é bastante expressivo, principalmente pela facilidade de produção destes artefatos no Brasil. Neste trabalho buscou-se avaliar a influência dos blocos cerâmicos, quando utilizados fora de norma, em uma determinada edificação, formada por um prédio residencial multifamiliar que estava sendo construído no município de Itaperuna, RJ e se encontrava nas etapas construtivas de vedação e revestimento, cujas perdas e causas associadas foram identificadas e quantificadas.

Palavras-chave: Blocos Cerâmicos, Construção Civil, Resíduos.

\section{COST ANALYSIS OF BUILDINGS DUE TO THE USE OF CERAMIC NON- STANDARDIZED BLOCKS}

\begin{abstract}
The construction industry is one of that most absorbs labor in Brazil, with a significant participation in the GDP of the order of $15 \%$. On the other hand, it is still a major generator of waste, which varies according to the raw material used and the disqualified labor force. Within this market range, the number of buildings that use ceramic blocks as sealing or structural elements is quite expressive, mainly due to the easiness of production of these artifacts in Brazil. This work aimed to evaluate the influence of ceramic blocks, when used outside of norm, in a given construction, formed by a multifamily residential building that was being built in the municipality of Itaperuna, Rio de Janeiro, which was in the constructive stages of sealing and coating, whose losses and associated causes were identified and quantified.
\end{abstract}

Keywords: Ceramic Blocks, Construction, Waste.

1 Instituto Militar de Engenharia, Doutorando em Ciência dos Materiais - Praça General Tibúrcio, 80, 22.290-270, Praia Vermelha, Urca, Rio de Janeiro - RJ, Brasil.

2 Instituto Militar de Engenharia, Professor, Ph.D. em Engenharia e Ciências dos Materiais - Praça General Tibúrcio, 80, 22.290-270, Praia Vermelha, Urca, Rio de Janeiro - RJ, Brasil.

3 Universidade Estadual do Norte Fluminense, Mestre em Engenharia Civil, Av. Alberto Lamego, 2000 - Parque Califórnia, Campos dos Goitacazes - RJ.

4 Universidade Estadual do Norte Fluminense, Professor, Dr. em Engenharia Civil, Av. Alberto Lamego, 2000 - Parque Califórnia, Campos dos Goitacazes - RJ.

5 Universidade Estadual do Norte Fluminense, Mestre em Engenharia Civil, Av. Alberto Lamego, 2000 - Parque Califórnia, Campos dos Goitacazes - RJ.

6 Universidade Estadual do Norte Fluminense, Mestre em Engenharia Civil, Av. Alberto Lamego, 2000 - Parque Califórnia, Campos dos Goitacazes - RJ.

7 Universidade Estadual do Norte Fluminense, Mestre em Engenharia Civil, Av. Alberto Lamego, 2000 - Parque Califórnia, Campos dos Goitacazes - RJ. 


\section{INTRODUÇÃO}

A indústria da construção civil ocupa uma posição de grande destaque na economia nacional, pois a cadeia produtiva em que se insere, responde por valores superiores a $15 \%$ do PIB (Produto Interno Bruto) nacional, sendo muito elevado o número de pessoas que direta ou indiretamente emprega [1].

Por outro lado, e a indústria que apresente maior demanda em quantidade e diversidade de materiais se comparada a outras indústrias. Sendo, portanto, a que mais consome recursos naturais, e também a indústria que mais gera resíduos. Estima-se que este setor produtivo absorva até $50 \%$ do total de recursos naturais consumidos pela sociedade.

O setor da construção civil envolve uma grande quantidade de agentes intervenientes e de produtos parciais que são gerados ao longo de todo o processo de produção. Por isso e muito importante que os materiais empregados possuam padrões normatizados para garantir o nível de qualidade do produto final, aliado a redução de custos e desperdícios.

As etapas de uma obra são inter-relacionadas, favorecendo a ocorrência de falhas que provocam consumos adicionais ao orçamento original. Por isso, o estudo das perdas e consumos na indústria da construção civil e tão complexo. Haja visto que, um erro em uma alvenaria, por exemplo, pode somar perdas em várias outras etapas.

Este trabalho teve por finalidade avaliar a influência dos blocos cerâmicos, quando utilizados fora de norma, em uma determinada obra formada por um edifício residencial multifamiliar, no município de Itaperuna, RJ e que se encontrava nas etapas construtivas de vedação e revestimento, cujas perdas e causas associadas foram identificadas e quantificadas.

\section{MATERIAIS E MÉTODOS}

A pesquisa foi realizada em uma obra localizada no município de Itaperuna, cidade do interior do estado do Rio de Janeiro. Devido à ausência e grandes empresas de construção civil na região, foi monitorada uma pequena empresa incorporada que construía principalmente empreendimentos imobiliários residenciais.

A obra consistia em edifício misto, residencial e comercial, com 8.329,66 $\mathrm{m}^{2}$ de área construída e 16 pavimentos, sendo o térreo de lojas comerciais e os primeiros cinco pavimentos de garagens, e os demais de apartamentos residenciais.

A obra foi monitorada nas fases de execução da alvenaria e revestimento, nos dois primeiros pavimentos. A alvenaria foi executada em blocos cerâmicos furados de 9x19x29 cm e revestimentos de argamassa composta por cimento, cal e areia misturados em betoneira no próprio canteiro de obras.

\subsection{TÉCNICAS DE OBSERVAÇÃO E ANALISE}

A metodologia adotada nesta pesquisa envolveu a utilização das seguintes técnicas: aplicação de questionário padrão, entrevistas informais, medições e registros fotográficos. 


\section{- Aplicação de Questionário Padrão e Entrevistas Informais}

Foi aplicado um questionário padronizado que serviu de diretriz para identificar as causas das perdas investigadas. A elaboração do questionário foi baseada nos procedimentos e técnicas recomendadas pela ABNT e manuais técnicos da construção civil. Os resultados obtidos no questionário foram apresentados intrinsecamente na discussão dos fatores que influenciaram a geração de perdas.

Além das questões respondidas no questionário adotado, foram feitas entrevistas informais com engenheiros, mestres de obras e operários dos almoxarifados, complementando as informações obtidas, buscando conhecer os procedimentos típicos de cada obra.

\section{- Medições}

Como os projetos das obras não apresentavam detalhes construtivos, foram feitas as seguintes medidas, com o objetivo de comparar os valores obtidos com padrões exigidos pelas normas da ABNT:

- Das dimensões dos pilares, das vigas e lajes, dos blocos cerâmicos e de cimento;

- Das espessuras das alvenarias e aduelas;

- Das larguras das juntas horizontais e verticais de assentamento;

- Das espessuras dos revestimentos internos e externos;

\section{- Registros Fotográficos}

Foi utilizada máquina fotográfica digital Sony, modelo DSC-w\% (5,1 mega pixels) para registrar as diversas etapas do processo construtivo da obra monitorada, para facilitar a análise dos resultados e comprovar as perdas identificadas.

\section{RESULTADOS E DISCUSSÃO}

Para uma melhor compreensão dos resultados e devido a quantidade de fatores que influenciam na geração de perdas do processo construtivo, bem como na complexidade de distingui-los, adotou-se apresentar, em conjunto com os resultados, alguns parâmetros e procedimentos, que estão de acordo com normas vigentes e manuais técnicos.

\section{Alvenaria}

\section{- Procedimentos de Recebimento, Armazenamento, e Transporte dos Tijolos}

No recebimento dos blocos cerâmicos, esses devem ser avaliados visualmente quanto a existência de trincas, fraturas, superfícies irregulares, deformações, homogeneidade e uniformidades na cor.

As normas brasileiras [2,3] estabelecem que as avaliações dimensionais e de planeza devem ser feitas segundo amostras de 24 unidades para tijolos cerâmicos e 20 unidades para blocos de cimento, coletados ao acaso, de cada caminhão, antes 
da descarga. Os blocos deverão ser dispostos em filas e medidas as dimensões com uma trena metálica, com precisão de um milímetro.

Quanto as dimensões nominais, o lote deverá ser aceito somente se o comprimento, a largura e a altura das medias dos blocos atenderem as especificações da norma, com tolerância de $3 \mathrm{~mm}$ para mais ou para menos. Os blocos para acabamentos em gesso deverão também atender não só a variação dimensional media, mas também a variação individual com limite de $3 \mathrm{~mm}$. Os blocos que não se adequarem as normas deverão ser rejeitados. A Tabela 1 apresenta as dimensões exigidas pela norma [2].

Tabela1: Principais Dimensões Nominais de Blocos [2].

\begin{tabular}{cccc}
\hline $\begin{array}{c}\text { Tipo }(\mathbf{L} \times \mathbf{C} \times \mathbf{H}) \\
(\mathbf{c m})\end{array}$ & $\begin{array}{c}\text { Largura (L) } \\
(\mathbf{m m})\end{array}$ & $\begin{array}{c}\text { Altura }(\mathbf{H}) \\
(\mathbf{m m})\end{array}$ & $\begin{array}{c}\text { Comprimento (C) } \\
(\mathbf{m m})\end{array}$ \\
\hline $10 \times 20 \times 20$ & 90 & 190 & 190 \\
$10 \times 20 \times 30$ & 90 & 190 & 290 \\
$10 \times 20 \times 40$ & 90 & 190 & 390 \\
\hline
\end{tabular}

Quanto à planeza das faces devera aproximar uma régua metálica plana na linha diagonal das superfícies dos blocos. O lote será rejeitado em caso de oito ou mais blocos encontrados defeituosos. O lote também só será aceito no caso da soma do número de tijolos defeituosos de duas amostras for igual ou inferior a 11 unidades.

$\mathrm{Na}$ estocagem, o local deve ser planejado adequadamente no sentido de evitar que esses componentes sejam colocados fora do canteiro de obras, evitando, assim, que recebam umidade, principalmente para os blocos de concretos que sofrem mais com a ação das chuvas, devido à porosidade dos mesmos.

A estocagem dos blocos deve ser preferência junto ao equipamento de transporte vertical e evitar locais com mas condições como terrenos inclinados.

Quanto ao empilhamento dos blocos, devem-se respeitar as alturas máximas recomendadas (Tabela 2), a fim de evitar instabilidade nas pilhas e respectivamente quebra de blocos.

Tabela 2: Altura Máxima Recomendada para pilhas de Blocos e Tijolos [4]

\begin{tabular}{|c|c|c|}
\hline Fonte & Componente & Altura recomendada $(\mathrm{m})$ \\
\hline NBR 8798 [4] & $\begin{array}{l}\text { Bloco de concreto vazado } \\
\text { simples para alvenaria } \\
\text { estrutural. }\end{array}$ & Menor ou igual a 2,0 \\
\hline
\end{tabular}

Nos casos dos blocos cerâmicos e blocos de cimento para a otimização das perdas durante $o$ transporte, e necessário que tais materiais sejam entregues embalados (sobre estrados e envoltos em plásticos) e paletizados no canteiro de obras facilitando a locomoção dentro da construção através de gruas ou de carrinhos porta-paletes, conforme mostra Figura 1 [5]. 


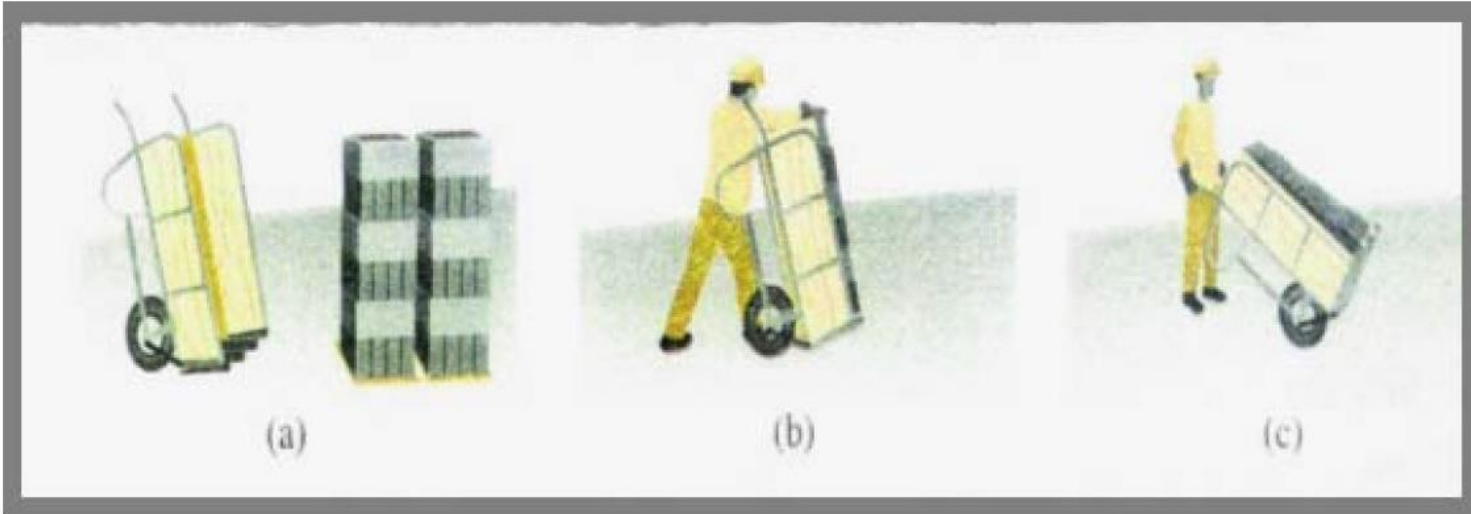

Figura 1: Transporte dos Blocos: (a) Carrinho vazio e mini-pallet de blocos preparado para o transporte; (b) Encaixe do mini-pallet; (c) Transporte

\section{- Das Observações, do Recebimento, Armazenamento e Transporte dos Tijolos}

$\mathrm{Na}$ obra estudada, os tijolos não foram entregues paletizados e embalados para evitar quebras durante o manuseio, por se tratar de material frágil. Neste caso, a conferencia tanto quantitativa como qualitativa (materiais em condições de uso) não foi realizada, pois os responsáveis pelo almoxarifado aceitavam os blocos quebrados, alegando que o fornecedor mandava material a mais.

Outro problema encontrado foi a diferença de medidas dos tijolos, tanto de um bloco para o outro, que variavam até $5 \mathrm{~mm}$, como na falta de padronização das medidas segundo a norma da ABNT [2]. As diferenças dimensionais chegaram a atingir valores de 1,5 a $2 \mathrm{~cm}$; ou seja, os tijolos especificados com espessura de $9 \mathrm{~cm}$ apresentaram espessura entre 7 e $7,5 \mathrm{~cm}$. Os tijolos cerâmicos também apresentaram superfícies irregulares, deformações e não-uniformidade de cor.

O transporte dos tijolos foi realizado em jericas ou carrinhos de mão, que são equipamentos inadequados, visto que esses apresentam forma arredondada, enquanto que os tijolos tem forma de paralelepípedo, proporcionando assim, a quebra das arestas. A Figura 2 mostra o transporte em carrinhos de mão, na obra analisada.

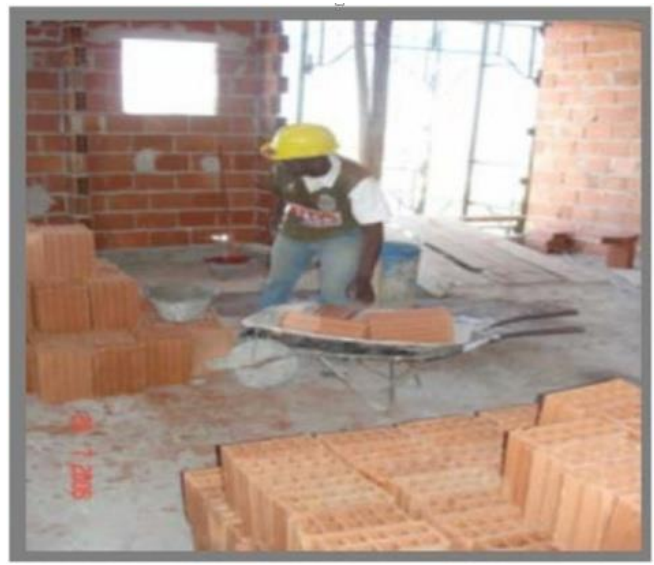

Figura 2: Transporte de Blocos Cerâmicos em Carrinhos de Mão 


\section{- Das observações da Execução das Alvenarias}

$\mathrm{Na}$ execução das alvenarias foi observado que as falhas de recebimento, estocagem e transporte dos blocos afetaram diretamente a construção de paredes.

A utilização de blocos e tijolos com arestas quebradas durante o transporte fazia com que os operários preenchessem os espaços vazios com argamassas e na execução das paredes foi observada incompatibilidade das dimensões dos blocos e das dimensões dos vãos da estrutura, anto na altura como no comprimento.

$\mathrm{Na}$ obra, também não havia projetos específicos de alvenaria de vedação, com modulação de componentes, como blocos seccionáveis, sendo necessário efetuar cortes nos tijolos para adequar as alturas e aos comprimentos da parede.

A necessidade de cortes se agravava, pois eram utilizados equipamentos inadequados, como colher de pedreiro ao invés de uma serra elétrica manual ou uma serra de bancada com disco refratário para corte de blocos.

A geração de entulho na execução das paredes foi excessiva (Figura 3), principalmente após o termino a execução das mesmas, devido aos rasgos para adequação das instalações como as de hidráulica e de elétrica.

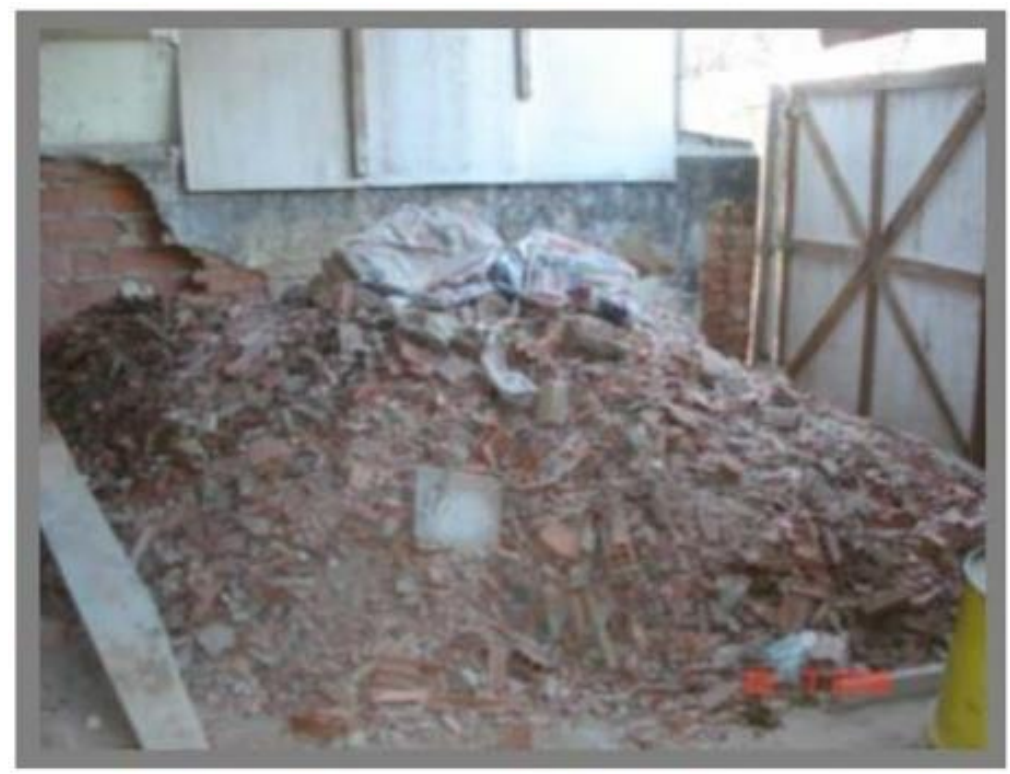

Figura 3: Rejeitos de Blocos Cerâmicos e Argamassas

$\mathrm{Na}$ observação dos serviços de revestimentos das paredes de alvenaria destacamse grandes desperdícios a utilização das argamassas que foram incorporadas aos mesmos para encobrir defeitos de execução. As espessuras das argamassas variaram de $2 \mathrm{~cm}$ a $4 \mathrm{~cm}$ em áreas secas e de $2,5 \mathrm{~cm}$ a $5 \mathrm{~cm}$ em áreas molhadas (preparadas para revestimentos cerâmicos).

Uma das principais causas da sobrespessura dos revestimentos foi a falta de coordenação entre projetos com estrutura e alvenaria, alvenaria e instalações, ausência de detalhes construtivos e de indicação das espessuras dos revestimentos. 
A incompatibilidade entre esses projetos trouxe problemas que não foram detectados previamente e que foram sanados nas obras pelos operários, através do aumento das espessuras dos revestimentos.

No monitoramento da obra, foi observado também, que vido aos desaprumos das alvenarias e das estruturas, como falta de nivelamento das lajes e das paredes e ausência de esquadro entre paredes perpendiculares, os operários amentavam a espessura dos revestimentos para fazer o nivelamento.

Ao comparar as espessuras especificas em projeto, com as medidas dos revestimentos em um determinado apartamento da obra, foram obtidos os valores para a diferença de espessura e volume revestido mostrados na Tabela 3, a seguir:

Tabela 3: Comparação entre Valores Projetados e Executados de Espessuras e Volumes de Revestimentos.

\begin{tabular}{|c|c|c|c|c|c|}
\hline \multirow[b]{2}{*}{ Compartimento } & \multicolumn{2}{|c|}{ Espessura } & \multirow{2}{*}{$\begin{array}{l}\text { Diferença de } \\
\text { Espessura } \\
\text { (cm) }\end{array}$} & \multicolumn{2}{|c|}{ Volume Revestido } \\
\hline & $\begin{array}{l}\text { Projeto } \\
\text { (cm) }\end{array}$ & $\begin{array}{l}\text { Executado } \\
\text { (cm) }\end{array}$ & & $\begin{array}{l}\text { Projeto } \\
\left(\mathrm{m}^{3}\right)\end{array}$ & $\begin{array}{c}\text { Executado } \\
\left(\mathrm{m}^{3}\right)\end{array}$ \\
\hline Sala & 1,0 & 2,0 & 1,0 & 0,558 & 1,116 \\
\hline Suíte & 1,0 & 2,0 & 1,0 & 0,467 & 0,933 \\
\hline Quarto 01 & 1,0 & 2,5 & 1,5 & 0,377 & 0,943 \\
\hline Quarto 02 & 1,0 & 2,5 & 1,5 & 0,339 & 0,848 \\
\hline Circulação & 1,0 & 2,0 & 1,0 & 0,112 & 0,223 \\
\hline Banheiro Social & 2,0 & 3,5 & 1,5 & 0,447 & 0,782 \\
\hline Banheiro Suíte & 2,0 & 3,5 & 1,5 & 0,468 & 0,819 \\
\hline \multirow[t]{2}{*}{ Cozinha } & 2,0 & 4,0 & 2,0 & 1,147 & 2,293 \\
\hline & & & Total: & 3,915 & 7,96 \\
\hline
\end{tabular}

Sendo, a perda física percentual definida pela equação A:

Perda fisica $=\frac{\text { quantidade de material necessario-quantidade de material gasto }}{\text { quantidade de material necessario }} \times 100 \% \quad(\mathrm{~A})$

Ao aplicar a Equação A, de perda física [6], obtém-se seguinte percentual de perda:

$$
\text { Perda fisica }=\frac{3,915-7,960}{3,915} \times 100=103 \%
$$

Portanto, o percentual de perda no apartamento estudado foi de $103 \%$ para os revestimentos internos.

Conforme orçamento da obra, o custo total de argamassas para o revestimento interno de um apartamento seria de $\mathrm{R} \$ 4.037,60$. Neste caso, uma perda de $103 \%$ representou um custo adicional de $R \$ 4.158,73$ em cada apartamento e um custo excedente em todo o prédio de $\mathrm{R} \$ 266.158,72$. 


\section{CONCLUSÕES}

A gestão de controle do consumo de materiais no canteiro de obra foi o grande alvo deste trabalho, porem com uma nova perspectiva: a observação da etapa de alvenaria como instrumento para a melhoria continua dos materiais empregados e dos serviços executados. Nesse aspecto, os resultados da pesquisa mostraram que há possibilidades potenciais de redução de rejeitos no próprio canteiro, através da padronização dos materiais e execução de serviços com técnicas aplicadas adequadamente em todas as etapas da obra.

As analises obtidas permitiram identificar as causas e as perdas mais comuns na execução da alvenaria, decorrentes de falta de critérios em etapas distintas como, recebimento, armazenamento e transporte dos materiais. Foram, portanto, observados blocos irregulares e desuniformes, confeccionados em desacordo com as normas da ABNT, quebra excessiva de tijolos e blocos para modulação da alvenaria e passagem das instalações, sobrespessura elevada das argamassas dos revestimentos para encobrir erros dos blocos cerâmicos empregados.

Outra constatação foi que a obra apresentou um grande índice de desperdício na etapa de revestimento, responsável por um enorme custo adicional na obra, devido a necessidade de encobrir erros em etapas anteriores a ase mencionada, e ao emprego de blocos cerâmicos sem qualidade e mão de obra desqualificada.

$\mathrm{Na}$ obra monitorada a falta de gerenciamento, coordenação das obras, projetos detalhamentos e modulados e profissionais treinados e qualificados foram às causas das perdas, contribuindo para improvisações empíricas e comuns nas obras.

No que se refere a questão financeira, constatou-se que as perdas dos blocos consideradas desprezíveis, quando avaliadas isoladamente, traziam para a construtora, custos adicionais bastante elevados, se incluídas nas proporções de toda a construção.

Elevar os padrões da qualidade dos materiais empregados no setor civil significa articulares os diversos agentes do processo e comprometê-los com a qualidade para garantir o padrão do produto final.

A necessidade de oferecer produtos de qualidade a um preço competitivo poderá ser um incentivo para que as empresas busquem a melhoria do processo, através do conhecimento dos recursos físicos nos canteiros de obras.

Além dos aspectos financeiros e dos aspectos de interesse direto das empresas da construção civil, a questão da geração de entulhos, da economia de energia e vital para que possamos viver em uma sociedade baseada no desenvolvimento sustentável.

\section{REFERÊNCIAS}

1. Construbusiness 2003 - Produto Interno Bruto. Disponível em: $<$ http://www.portaldaconstruçao.com.br/construbusiness.htm>. Acesso em 03 out. 2005.

2. Associação Brasileira de Normas Técnicas (ABNT). Bloco cerâmico para alvenaria. Especificação: NBR7171. Rio de Janeiro. 1992 
3. Associação Brasileira de Normas Técnicas. Blocos vazados de concreto simples para alvenaria sem função estrutural. Especificação: NBR 7173. Rio de Janeiro. 1982

4. Associação Brasileira de Normas Técnicas (ABNT). Execução e controle de obras em alvenaria estrutural de blocos vazados de concreto. Especificação: NBR 8798. Rio de Janeiro. 1995

5. Souza R, Mekbekian G. Qualidade na aquisição de materiais execução de obra. Editora Pini, São Paulo. 1a ed. p.153. 1996

6. Souza UEL. Como reduzir perdas nos canteiros: manual de gestão do consumo de materiais na construção civil, Editora Pini, São Paulo, $1^{1 \mathfrak{a}}$ ed. p 25. 2005 